\title{
ANALISIS KELAYAKAN USAHA PUPUK ORGANIK (PO) CURAH
}

\author{
Oleh : \\ CECEP PARDANI \\ FAKULTAS PERTANIAN UNIVERSITAS GALUH CIAMIS \\ e-mail :alfarhanic@gmail.com \\ DEVI SUTRIANA
FAKULTAS PERTANIAN UNIVERSITAS GALUH CIAMIS \\ e-mail :devisutriana@gmail.com
}

\begin{abstract}
Abstrak
Tujuan dari penelitian ini adalah untuk mengetahui : (1) Kelayakan finansial usaha pupuk organik curah pada Kelompok Tani Serang Kuning di Desa Salakaria Kecamatan Sukadana Kabupaten Ciamis, (2) Jangka waktu yang diperlukan untuk mengembalikan seluruh modal yang diinvestasikan pada usaha pupuk organik curah Kelompok Tani Serang Kuning di Desa Salakaria Kecamatan Sukadana Kabupaten Ciamis.

Metode yang digunakan dalam penelitian ini adalah metode studi kasus pada Kelompok Tani Serang Kuning yang berada di Desa Salakaria Kecamatan Sukadana Kabupaten Ciamis. Penarikan sampel dilakukan secara purposive. Analisis yang digunakan dalam penelitian ini adalah analisis kelayakan usaha/finansial yaitu dengan menggunakan rumus NPV, IRR, Net B/C dan Payback Periods.

Hasil analisis menunjukkan :

1. Nilai $N P V$ sebesar Rp. 443.274.340,- berarti responden memperoleh keuntungan pada tingkat bunga 12 persen sebesar Rp. 443.274.340,-. Nilai Net B/C sebesar 1,43 ini berarti setiap 1,00 modal yang ditanam pada usaha pupuk organik curah akan memperoleh manfaat sebesar 1,43. Nilai $I R R$ yang diperoleh sebesar 28 persen, berarti tingkat bunga bank maksimum yang mampu dibayar oleh responden sebesar 28 persen per tahun atau lebih besar dari tingkat bunga 12 persen. Dilihat dari nilai $N P V$, Net $B / C$ dan IRR maka usaha pupuk organic curah di Desa Salakaria layak untuk diusahakan, karena nilai $N P V$ nya lebih dari $0, N e t B / C$ lebih dari 1 , dan $I R R$ nya lebih besar dari tingkat bunga bank yang berlaku.
\end{abstract}

2. Jangka waktu pengembalian modal yang diinvestasikan dalam kegiatan usaha pupuk organik curah pada kelompok tani di Desa Salakaria yaitu 2 tahun 5 bulan 21 hari.

Kata Kunci : Analisis kelayakan usaha/finansial , NPV, IRR, Net B/C dan Payback Periods.

\section{PENDAHULUAN}

Pembangunan Pertanian yang tangguh,efektif dan efisien perlu ditingkatkan dalam menciptakan pembangunan nasional dalam rangka peningkatan Swansembada pangan yang berkelanjutan dalam rangka Kedaulatan Pangan. Pembangunan pertanian dapat diartikan sebagai penyebaran dari inovasi teknologi pertanian bagi para petani, sehingga diharapkan produktivitas usaha pertanian dapat meningkat.

Agroindustri merupakan usaha untuk meningkatkan efisiensi sektor pertanian hingga menjadi kegiatan yang sangat produktif melalui proses modernisasi pertanian. Modernisasi di sektor industri dalam sekala nasional dapat meningkatkan penerimaan nilai tambah sehingga pendapatan ekspor akan lebih besar (Saragih, 2004).

Sistem agribisnis terdiri dari beberapa subsistem : 1) Subsistem pengadaan dan penyaluran sarana produksi dan peralatan pertanian, 2) Subsistem usahatani, 3) Subsistem pengolahan hasil pertanian, 4) Subsistem penunjang, 5) Subsistem distribusi dan pemasaran.

Penggunaan pupuk organik ini diharapkan dapat menekan biaya produksi dan 


\section{A MIMBAR AGRIBISNIS \\ ISSN 2460-432. \\ Volume 1 - Nomor 3 - Juli 2016}

mendukung kelestarian lingkungan. Pupuk organik sangat baik dalam memperbaiki struktur tanah dimana sumber utama bahan organik dapat berasal dari lapukan sisa-sisa tanaman, hewan, dan manusia.
Berdasarkan data di Kabupaten Ciamis, terdapat 5 kelompoktani yang mengusahakan pupuk organik yang tersebar di 5 Kecamatan.

Tabel 1. Kelompoktani Pupuk Organik di Kabupaten Ciamis Tahun 2014

\begin{tabular}{|c|l|l|l|}
\hline No & \multicolumn{1}{|c|}{$\begin{array}{c}\text { Nama } \\
\text { Kelompoktani }\end{array}$} & \multicolumn{1}{|c|}{ Alamat } & \multicolumn{1}{|c|}{$\begin{array}{c}\text { Rata-rata Produksi } \\
\text { (kg/bulan) }\end{array}$} \\
\hline 1. & Serang kuning & Ds. Salakaria Kec. Sukadana & 10.500 \\
2. & Tri jaya & Ds. Situmandala Kec. Sukadana & 10.000 \\
3. & Tirta jaya & Ds. Karangpawitan Kec. Padaherang & 9.500 \\
4. & Kaurohani & Ds. Sirnajaya Kec. Rajadesa & 8.000 \\
5. & Sinar mukti & Ds. Kawasen Kec. Banjarsari & 7.000 \\
6. & Sumber makmur & Ds. Kaso Kec. Tambaksari & 6.000 \\
\hline \multicolumn{2}{|l}{} & \multicolumn{1}{|l}{ Jumlah } & $\mathbf{5 1 . 0 0 0}$ \\
\hline
\end{tabular}

Sumber : Dinas Pertanian Tanaman Pangan Kabupaten Ciamis, 2014.

Perajin akan memperoleh pendapatan (keuntungan) apabila penerimaan yang diperoleh lebih besar dari biaya produksi yang dikeluarkan, sedangkan penerimaan merupakan perkalian antara jumlah produksi dengan harga jual (Rahadja dan Manurung, 2008).

Peningkatan pendapatan pupuk organik dapat terjadi apabila diiringi dengan peningkatan teknologi dan mutu walaupun dibutuhkan investasi yang cukup besar. Umur ekonomis adalah jangka waktu pemanfaatannya secara ekonomis atau umur dari suatu aset yang berakhir hingga secara ekonomi penggunaan aset tersebut tidak menguntungkan lagi secara ekonomi, walaupun secara teknis aset tersebut masih dapat digunakan (Prabowo, 2006).

Salah satu fungsi analisis finansial adalah untuk mengetahui berapa lama modal yang kita investasikan akan kembali, seberapa cost benefit yang kita raih dengan korbanan cost yang telah kita keluarkan.

\section{Identifikasi Masalah}

Berdasarkan uraian pada latar belakang, maka masalah-masalah yang dapat diidentifikasikan adalah sebagai berikut :

1.

Bagaimana

kelayakan finansial pupuk organik yang diusahakan, Berapa lama jangka waktu yang diperlukan untuk mengembalikan seluruh modal yang diinvestasikan kelompok tani Serang Kuning di Desa Salakaria Kecamatan sukadana Kabupaten Ciamis?

\section{Tujuan Penelitian}

Penelitian ini dilaksanakan dengan tujuan untuk mengetahui :

1)

Kelayakan finansial pupuk organik yang diusahakan, Jangka waktu yang diperlukan untuk mengembalikan seluruh modal yang diinvestasikan oleh kelompok tani Serang Kuning di Desa Salakaria Kecamatan Sukadana Kabupaten Ciamis.

\section{Kegunaan Penelitian}

Hasil penelitian ini diharapkan dapat bermanfaat dan berguna bagi :

1. Peneliti, agar mengetahui kelayakan finansial pada usaha pupuk organik.

2. Pengusaha, sebagai bahan pertimbangan dalam menetapkan perencanaan dan langkah-langkah kegiatan selanjutnya dalam mengelola usahanya.

3. Pemerintah atau instansi terkait, sebagai bahan masukan dan pertimbangan dalam menentukan kebijakan untuk pengembangan agroindustri di pedesaan. 


\section{Analisis Kelayakan Usaha Pupuk Organik (PO) Curah}

CECEP PARDANI DAN DEVI SUTRIANA

4. Peneliti lain, sebagai informasi awal dalam pelaksanaan penelitian selanjutnya.

\section{Kerangka Pemikiran}

Pada pupuk organik biaya produksi yang digunakan dibagi menjadi dua bagian, yaitu biaya investasi dan biaya operasional. Menurut Husnan dan Muhamad (2008), biaya investasi adalah seluruh biaya yang dikeluarkan sejak persiapan lahan sampai dengan usahatani tersebut berjalan, sedangkan biaya operasional adalah seluruh biaya yang dikeluarkan selama proses produksi berlangsung, artinya secara rutin biaya tersebut harus dikeluarkan.

Selanjutnya Husnan dan Muhamad (2008) menyatakan, bahwa ada beberapa analisis yang biasa digunakan dalam evaluasi proyek, yaitu:

1) Analisis Finansial (Financial Analysis)

2) Analisis Ekonomi (Economic Analysis).

Alat ukur yang digunakan untuk menentukan apakah suatu proyek layak atau tidak untuk diusahakan disebut kriteria investasi yang terdiri dari Net Present Value (NPV), Net Benefit Of Cost Ratio (Net B/C) dan Internal Rate Of Return (IRR). Sedangkan untuk mengukur kecepatan kembalinya modal yang diinvestasikan digunakan Payback Period yaitu jangka waktu kembalinya modal yang diinvestasikan melalui keuntungan yang diperoleh dari suatu proyek (Husnan dan Muhamad, 2008)

\section{METODE PENELITIAN Jenis Penelitian}

Jenis penelitian yang digunakan dalam penelitian ini adalah studi kasus pada kelompoktani Serang Kuning di Desa Salakaria Kecamatan Sukadana Kabupaten Ciamis. Menurut Daniel 2002, studi kasus merupakan penelitian pada objek yang akan diteliti lebih terarah atau terfokus pada sifat tertentu yang tidak berlaku umum.

\section{Operasionalisasi Variabel}

Menyamakan dan memperjelas pemahaman dalam penelitian ini, maka variabel-variabel yang akan diteliti dapat dioperasionalisasikan sebagai berikut :
1. Biaya adalah korbanan sumber ekonomi yang diukur dalam satuan uang yang telah terjadi atau kemungkinan akan terjadi untuk tujuan tertentu dan dinilai dalam satuan rupiah.

2. Biaya investasi adalah seluruh biaya yang dikeluarkan mulai proyek tersebut dilaksanakan sampai proyek tersebut mulai berjalan (beroperasi). Yang dinilai dalam satuan rupiah, yang meliputi: Pendirian bangunan pabrik, dihitung berdasarkan luas bangunan, yang dinyatakan dalam satuan meter persegi, dan dinilai dalam satuan rupiah.Pembelian mesin dan alat, dihitung dalam satuan unit dan dinilai dalam satuan rupiah.Pendaftaran Perusahaan yang meliputi Surat Izin usaha Perdagangan (SIUP) dan Sertifikasi Produksi Pangan Industri Rumah tangga (SPPIRT), dihitung dalam satuan unit, dan dinilai dalam satuan rupiah.

3. Biaya Operasional adalah seluruh biaya yang dikeluarkan selama proses produksi itu berlangsung, artinya secara rutin biaya ini harus dikeluarkan. Biaya operasional terdiri dari:

a. Pembelian bahan baku

a) Kotoran Sapi, Dedak kasar , Hijauan, dihitung dalam satuan kwintal dan dinilai dalam satuan rupiah.

b) Mikro organisme, dihitung dalam satuan liter dan dinilai dalam satuan rupiah.

b. Pembelian bahan bakar, dihitung dalam satuan liter, dan dinilai dalam satuan rupiah.

c. Karung plastik, dihitung dalam satuan buah dan dinilai dalam satuan rupiah.

d. Pembelian benang, dihitung dalam satuan rol dan dinilai dalam satuan rupiah.

e. Pembelian oli, dihitung dalam satuan liter dan dinilai dalam satuan rupiah.

f. Tenaga kerja, dihitung berdasarkan Hari Orang Kerja (HOK), dan dinilai dalam satuan rupiah.

g. Pajak bumi dan bangunan, dihitung dalam satuan tahun dan dinilai dalam satuan rupiah. 


\section{A MIMBBAR \\ ISSN 2460-4321 \\ Volume $1 \bullet$ Nomor $3 \bullet$ Juli 2016}

h. Pajak usaha dihitung dalam satuan tahun dan dinilai dalam satuan rupiah.

i. Perbaikan mesin dihitung dalam satuan rupiah.

4. Penerimaan adalah jumlah produksi dikalikan dengan harga satuan produksi, yang dinilai dalam satuan rupiah per tahun.

5. Pendapatan adalah selisih antara penerimaan dengan biaya dan dinilai dalam satuan rupiah per tahun.

6. Net Present Value (NPV) adalah selisih antara penerimaan dengan pengeluaran yang dinilai dengan nilai sekarang.

7. Net Benefit Cost (B/C) Ratio adalah perbandingan antara benefit bersih dengan biaya bersih.

8. Internal Rate of Return (IRR) adalah kemampuan suatu proyek untuk menghasilkan suatu returns atau tingkat keuntungan yang dicapainya.

9. Payback Periods adalah jangka waktu kembalinya investasi yang telah dikeluarkan melalui keuntungan yang diperoleh dari pupuk organik.

10. Bunga bank yang dihitung adalah bunga bank yang berlaku di bank BRI Unit Ciilat.

Asumsi yang digunakan dalam penelitian ini adalah Harga input dan output tetap selama periode analisis, Semua hasil produksi habis terjual, Harga produk adalah harga yang berlaku pada saat penelitian.,Periode analisis sesuai dengan umur ekonomis mesin yaitu 4 tahun.

\section{Teknik Pengumpulan Data}

Data yang dikumpulkan dalam penelitian ini terdiri dari data primer dan data sekunder.

\section{Teknik Penarikan Sampel}

Teknik pengambilan sampel dilakukan secara sengaja (Purposive Sampling) terhadap kelompoktani Serang Kuning di Desa Salakaria Kecamatan Sukadana Kabupaten Ciamis. Menurut Sugiono (2006), Purposive Sampling adalah teknik penarikan sampel yang dilakukan secara sengaja (sengaja dipilih berdasarkan tujuan tertentu dari peneliti)

\section{Rancangan Analisis Data}

Untuk mengetahui bagaimana kelayakan finansial pupuk organik pada kelompok tani Serang Kuning, dapat dihitung dengan menggunakan metode-metode menurut Husnan dan Muhammad (2005) sebagai berikut :

1) Net Present Value (NPV)

$$
\begin{aligned}
& \mathrm{NPV}=\sum_{i=1}^{n} N B_{i}(1+i)^{-n} \\
& \text { atau } \\
& \mathrm{NPV}=\sum_{i=1}^{n} \frac{N B_{i}}{(1+i)^{n}}
\end{aligned}
$$

Ketêangan :

NBNPE Netbe

$\mathrm{C}=$ Biayal Investasi + Biaya

operasional

$\mathrm{B}=$ Benefit yang telah didiskon

$\mathrm{i}=$ Diskon faktor

$\mathrm{n} \quad=\operatorname{tahun}$ (waktu)

Kriteria:

NPV > 0 (nol) $\rightarrow$ Usaha/proyek layak

(feasible) untuk dilaksanakan

NPV $<0$ (nol) $\rightarrow$ Usaha/proyek tidak

layak (feasible) untuk dilaksanakan

$\mathrm{NPV}=0(\mathrm{nol}) \rightarrow$ Usaha/proyek berada

dalam keadaan BEP

2) Net Benefit Cost Ratio

Net $\mathrm{B} / \mathrm{C}=\frac{\sum_{i=1}^{n} N \overline{B_{i}}(+)}{\sum_{i=1}^{n} N \overline{B_{i}}(-)}$

Net $\mathrm{B} / \mathrm{C}=$ Net Benefit Cost Ratio

$\mathrm{N} \bar{B}_{i}(+)=$ Net Benefit yang telah didiskon positif

$\mathrm{N} \bar{B}_{i}(-)=$ Net Benefit yang telah didiskon negatif

Kriteria :

Net B/C> 1 (satu) berarti proyek (usaha) layak dikerjakan

Net $\mathrm{B} / \mathrm{C}<1$ (satu) berarti proyek tidak layak dikerjakan

Net $\mathrm{B} / \mathrm{C}=1$ (satu) berarti cash in flows = cash out flows (BEP) atau

$\mathrm{TR}=\mathrm{TC}$

\section{Internal Rate of Return}

$$
\mathrm{IRR}=i_{1}+\frac{N P V_{1}}{\left(N P V_{1}-N P V_{2}\right)}\left(i_{2}-i_{1}\right)
$$


Keterangan :

IRR = Internal Rate of Return

$\mathrm{i}_{1} \quad=$ Tingkat bunga (discount rate) pertama dimana diperoleh NPV positif

$\mathrm{i}_{2} \quad=$ Tingkat bunga (discount rate) kedua dimana diperoleh NPV negatif

$\mathrm{NPV}_{1}=\mathrm{NPV}$ pertama yang benilai positif $\mathrm{NPV}_{2}=\mathrm{NPV}$ kedua yang bernilai negatif Kriteria :

IRR> SOCC maka proyek dikatakan layak

IRR = SOCC berarti proyek pada BEP

IRR $<$ SOCC dikatakan bahwa proyek tidak layak.

SOCC $=$ Social Opportunity Cost of

Capital/tingkat bunga relevan

\section{Payback Periods (PP)}

Untuk menghitung lama periode yang diperlukan dalam mengembalikan uang yang telah diinvestasikan dari aliran kas masuk tahunan yang dihasilkan oleh proyek, maka menggunakan rumus sebagai berikut, Suliyanto (2010).

$\mathrm{PP}=T_{p-1}+\frac{\text { Akumulasikas masuksebelumPP }}{\text { Aruskas bersihpadaPP }} \times 1$ tahun

Keterangan :

$\mathrm{PP}=$ Payback Periods

$T_{\mathrm{p}-1}=$ Tahun sebelum terdapat $\mathrm{PP}$

\section{Tempat dan Waktu Penelitian}

Penelitian ini dilaksanakan di kelompoktani Serang Kuning di Desa Salakaria Kecamatan Sukadana Kabupaten Ciamis.

\section{HASIL DAN PEMBAHASAN}

Keadaan Umum Daerah Penelitian

Desa Salakaria merupakan salah satu desa di Kecamatan Sukadana Kabupaten Ciamis, terletak sekitar 2 kilometer dari Ibukota Kecamatan Sukadana.Secara geografis batasbatas wilayah Desa Salakaria adalah Sebelah Utara berbatasan dengan Desa Mekarsari Kecamatan Cipaku.,Sebelah Timur berbatasan dengan Desa Ciparigi Kecamatan
Sukadana.,Sebelah Selatan berbatasan dengan Desa Karangampel Kecamatan Baregbeg, Sebelah Barat berbatasan dengan Desa Sukadana Kecamatan Sukadana.

\section{Analisis Kelayakan Usaha Pupuk Organik \\ 1. Biaya Investasi}

Biaya investasi yang dihitung dalam penelitian ini meliputi pendirian bangunan pabrik, pembelian mesin dan peralatan lainnya.

Tabel 6. Biaya Investasi Usaha Pupuk

Organik

\begin{tabular}{|c|l|c|c|}
\hline No & $\begin{array}{l}\text { Jenis Biaya } \\
\text { Investasi }\end{array}$ & $\begin{array}{c}\text { Jumlah } \\
(\mathbf{R p})\end{array}$ & $\begin{array}{c}\text { Persentase } \\
(\mathbf{\%})\end{array}$ \\
\hline 1 & $\begin{array}{l}\text { Pendirian } \\
\text { bangunan }\end{array}$ & 36.000 .000 & 11,69 \\
2 & $\begin{array}{l}\text { Pabrik } \\
\text { Pembelian } \\
\text { mesin dan } \\
\text { peralatan } \\
\text { lainnya }\end{array}$ & 272.110 .000 & 88,31 \\
\hline & Jumlah & $\mathbf{3 0 8 . 1 1 0 . 0 0 0}$ & $\mathbf{1 0 0 , 0 0}$ \\
\hline
\end{tabular}

Sumber : Perusahaan Pupuk Organik

\section{Biaya Operasional}

Biaya operasional yang dikeluarkan untuk usaha pupuk organik di kelompoktani Serang Kuning setiap tahunnya relatif sama, penggunaan biaya operasional yaitu untuk pembelian bahan baku, upah tanaga kerja, bahan bakar.

\section{Penerimaan}

Penerimaan merupakan hasil perkalian antara jumlah produk dengan harga jual produk tersebut. Penerimaan dalam usaha pupuk organik di kelompok tani Serang Kuning diperoleh dari penjualan hasil produksi pupuk organik.

Total penerimaan selama 4 tahun yaitu sebesar Rp 1.872.000.000,- dan mulai menghasilkan pada tahun pertama

\section{Analisis Kelayakan Finansial}

Usaha pupuk organik di Desa Salakaria Kecamatan Sukadana Kabupaten Ciamis secara analisis ekonomi dapat diketahui dengan menghitung NPV, Net B/C, dan IRR, 


\section{A MIMBBAR \\ ISSN 2460-4321 \\ Volume $1 \bullet$ Nomor $3 \bullet$ Juli 2016}

Tabel 7. NPV, Net B/C dan IRR pada Usaha

Pupuk Organik yang Diusahakan Kelompok tani Serang Kuning di Desa Salakaria Kecamatan Sukadana.

\begin{tabular}{|c|l|c|}
\hline No & \multicolumn{1}{|c|}{ Uraian } & \multicolumn{1}{|c|}{ Jumlah } \\
\hline 1. & Net Present Value & Rp. 43.274.340,00 \\
2. & $($ NPV $12 \%$ & 1,43 \\
3. & $\begin{array}{l}\text { Net Benefit of Cost } \\
\text { Ratio (Net B/C) } \\
\text { Internal Rate of Return } \\
(\text { IRR })\end{array}$ & \\
\hline
\end{tabular}

Suatu usaha dikatakan layak (menguntungkan) jika nilai NPV usaha tersebut lebih besar dari 0 (NPV>0). Nilai NPV lebih besar dari 0 yaitu 443.274 .340 pada tingkat suku bunga $12 \%$. Maka dapat disimpulkan bahwa usaha pupuk organik di Desa Salakaria menguntungkan dan layak untuk diusahakan.

Kelayakan usaha ditinjau dari Net B/C dikatakan layak atau bermanfaat bilai nilai Net $\mathrm{B} / \mathrm{C}$ lebih besar dari 1 (Net $\mathrm{B} / \mathrm{C}>1)$. nilai Net B/C lebih besar dari 1 yaitu 1,43. Disimpulkan bahwa usaha pupuk organik di Desa Salakaria layak untuk diteruskan dan nilai IRR sebesar $28 \%$, hal ini menunjukkan bahwa usaha pengolahan teh layak untuk di teruskan, karena nilainya lebih besar dari SOCC (Social Opportunity Cost of Capital) yaitu sebesar $12 \%$.

\section{Payback Periods}

Payback Periods bukan merupakan kriteria kelayakan, namun Payback Periods diartikan sebagai jangka waktu kembalinya investasi yang telah dikeluarkan, melalui keuntungan yang diperoleh suatu proyek. Hal ini biasanya digunakan oleh pemilik modal untuk mengukur berapa lama kemampuan proyek dapat mengembalikan pinjaman. Semakin cepat Payback Periods, semakin baik untuk diusahakan. Dari hasil penelitian, bahwa jangka waktu tercapainya Payback Periods pada usaha pupuk organik di Desa Salakaria adalah 2 tahun 5 bulan 21 hari.

\section{PENUTUP}

Berdasarkan hasil penelitian dan pembahasan, maka dari penelitian tentang pupuk organik curah di kelompok tani Serang Kuning Desa Salakaria Kecamatan Sukadana
Kabupaten Ciamis dapat ditarik kesimpulan bahwa:

Usaha pupuk organik curah di kelompok tani Serang Kuning Desa Salakaria menguntungkan dan layak untuk dilanjutkan, dengan nilai NPV yang diperoleh pada tingkat bunga $12 \%$ sebesar 443.274 .340 , nilai $\mathrm{Net} \mathrm{B} / \mathrm{C}$ sebesar 1,43 dan IRR sebesar 28 persen, Jangka waktu yang dibutuhkan untuk dapat mengembalikan modal yang diinvestasikan pada usaha pupuk organik curah di kelompoktani Serang Kuning Desa Salakaria Kecamatan Sukadana Kabupaten Ciamis adalah 2 tahun 5 bulan 21 hari

Berdasarkan kesimpulan tersebut, Usaha Pupuk Organik Kelompok Tani Serang Kuning di Desa Salakaria Kecamatan Sukadana sebaiknya diteruskan dengan meningkatkan nilai investasinya karena berdasarkan hasil analisis usaha pupuk organik tersebut layak diusahakan. Perajin, diharapkan tetap konsisten terhadap kualitas, kontinuitas, dan kuantitas agar perusahaan berjalan dengan baik.

\section{DAFTAR PUSTAKA}

Anjayani, Eni dan Tri Haryanto. 2009. Geografi Untuk Kelas X SMA/MA. Jakarta: pusat perbukuan, Departemen Pendidikan Nasional.

Balai Penyuluhan Pertanian Perikanan dan Kehutanan (BP3K) Kecamatan Sukadana, 2015. Programa Penyuluhan Pertanian. Kabupaten Ciamis.

Desa Salakaria, 2015. Monografi Desa Salakaria. Sukadana.

Dinas Pertanian Tanaman Pangan Kabupaten Ciamis, 2015. Laporan Tahunan 2015. Ciamis.

Husnan, S. dan Muhamad, S. 2005. Studi Kelayakan Proyek. Unit Penerbit dan percetakan. Yogyakarta.

Prabowo. 2006. Akuntansi perpajakan terapan.PT. Grasindo. Jakarta.

Rahardja, P. dan Manurung, M. 2008. Pengantar Ilmu Ekonomi (Mikroekonomi dan Makroekonomi) Edisi Ketiga. Fakultas Ekonomi Universitas Indonesia. Jakarta. 


\section{Analisis Kelayakan Usaha Pupuk Organik (PO) Curah}

\section{CECEP PARDANI DAN DEVI SUTRIANA}

Saragih B, 2001. Agribisnis. Paradigma Pembangunan Ekonomi Berbasis Pertanian. Loji Grafika Griya Sarana. Bogor.

2004. Membangun Pertanian Dalam Perspektif Agrobisnis Dalam Ruang. Raja Grafindo Persada. Jakarta.

Sugiono. 2006. Metode Penelitian Bisnis. AlfaBeta. Bandung.

Suliyanto. 2010. Studi Kelayakan Bisnis. ANDI. Yogyakarta. 


\section{A MIMBAR \\ A GRIBISNIS \\ ISSN 2460-4321}

Volume 1 • Nomor $3 \bullet$ Juli 2016 